University of Rhode Island

DigitalCommons@URI

Open Access Master's Theses

2005

\title{
A Theoretical Approach to Study the Perception of Women as Credible Leaders in Male-Dominated Organizations
}

Regina A. Bell

University of Rhode Island

Follow this and additional works at: https://digitalcommons.uri.edu/theses

\section{Recommended Citation}

Bell, Regina A., "A Theoretical Approach to Study the Perception of Women as Credible Leaders in MaleDominated Organizations" (2005). Open Access Master's Theses. Paper 1633.

https://digitalcommons.uri.edu/theses/1633

This Thesis is brought to you for free and open access by DigitalCommons@URI. It has been accepted for inclusion in Open Access Master's Theses by an authorized administrator of DigitalCommons@URI. For more information, please contact digitalcommons-group@uri.edu. 


$$
\begin{aligned}
& B F 637 \\
& L 4 \\
& B 455 \\
& 2009
\end{aligned}
$$

A THEORETICAL APPROACH TO STUDY THE PERCEPTION OF WOMEN AS CREDIBLE LEADERS

IN MALE-DOMINATED ORGANIZATIONS

BY

REGINA A. BELL

A THESIS SUBMITTED IN PARTIAL FULFILLMENT OF THE REQUIREMENTS FOR THE DEGREE OF

MASTER OF ARTS

IN

COMMUNICATION STUDIES

UNIVERSITY OF RHODE ISLAND

2005 


\begin{abstract}
This study is intended to conduct a theoretical analysis of the perception of women as credible leaders in male-dominated organizations and its association with advancement. The factors associated with the failure of women to advance to leadership positions were examined and whether credibility contributes to this failure to advance. Inspired by the words of Roderick Hart, "What one studies inevitably affects how one studies it," I have approached this study with an analytical style to dissect pertinent theoretical perspectives (Hart, 1994, p. 75).

This study involved 120 participants from the Store Support Center of Consumer Value Store (CVS) located in Woonsocket, Rhode Island. The participants completed a survey based on the McCroskey Source Credibility Scale to assess the relationship between source credibility and advancement. Two surveys were distributed: Survey One requested employees to indicate how they felt his/her manager or supervisor felt about them as an employee. Survey Two was distributed to a total of fourteen managers requesting their perceptions of their male or female employees. In addition, pertinent information was gleaned from participants who responded to a research question about barriers they encounter regarding advancement to a leadership or management position. In particular, participants were asked to indicate if credibility is considered a barrier to advancement in a male-dominated organization.
\end{abstract}

The results indicated that, first, no significant difference exists between men and women's perceived credibility in a male-dominated organization. Secondly, no significant data support the claim that women are not advancing at the same rate as men in a male-dominated organization. Important to this study are the obstacles to 
advancement identified by the participants, among which include family responsibilities, lack of mentoring programs and limited work-related experience. 


\section{Acknowledgements}

The experience of attending Graduate School at the University of Rhode Island was a memorable experience for me. I was fortunate to have met many outstanding professors and students during this chapter of my life. This learning experience was extremely rewarding for me and has enhanced my personal and professional development.

Attaining this goal was only made possible by the unwavering support of my family. Without the genuine support of my husband, Rick, this experience would not have been possible. It is with much love that I dedicate my thesis to my husband, Rick. As always, I would like to thank my parents, Raymond and Elizabeth Germershausen, and my sister, Mary Germershausen, for their constant support, interest and enthusiasm.

Attending graduate school is truly a commitment. It is with sincere gratitude that I thank my committee: Dr. Abran Salazar, my advisor; Dr. Laura Beauvais; Dr. Norbert Mundorf and Dr. Kathleen Torrens. Thank you for creating a positive learning experience for me.

Finally, I would like to acknowledge a special person in the Communication Studies Department at the University of Rhode Island. Anyone who comes in contact with Linda Palmer recognizes her special qualities, particularly her contagious sense of humor. She is truly an ambassador for the Communication Studies Program. Linda, thank you for all that you do to make graduate school a memorable and positive experience. You're the best! 


\section{Table of Contents}

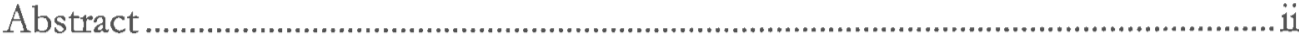

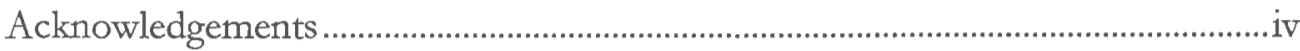

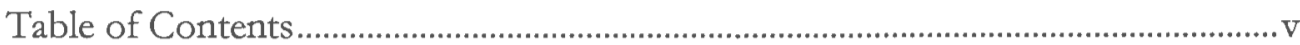

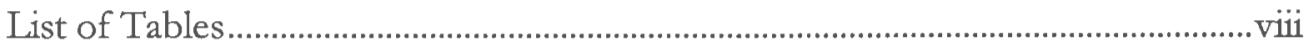

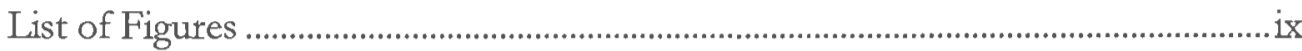

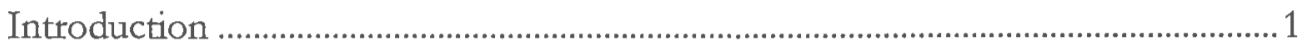

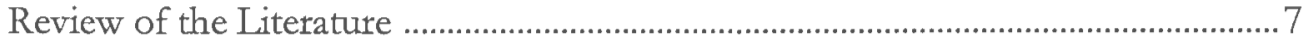

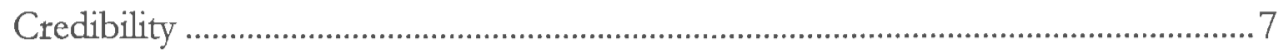

Organizational Dynamics: Networking ............................................................. 8

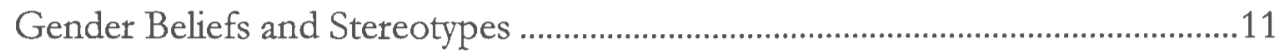

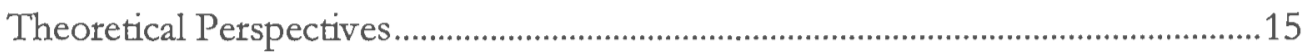

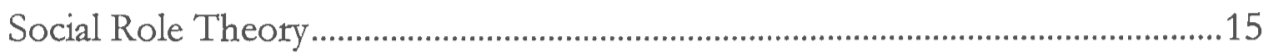

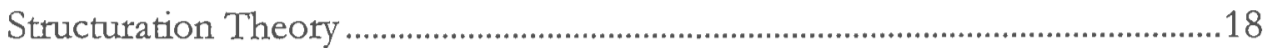

Summary of Theoretical Research........................................................................22

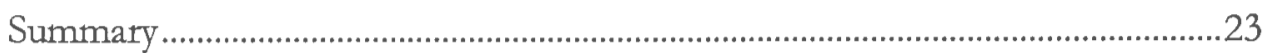

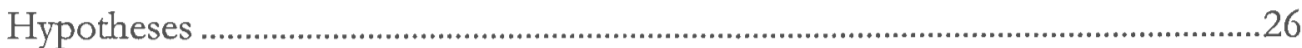

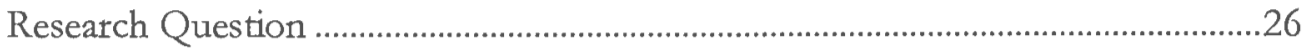

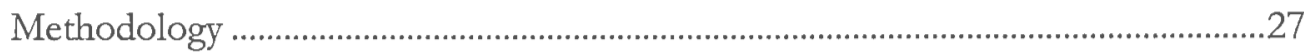

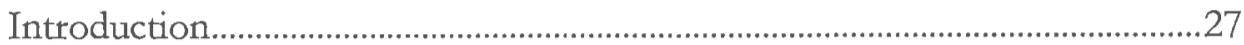

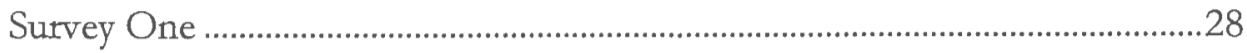

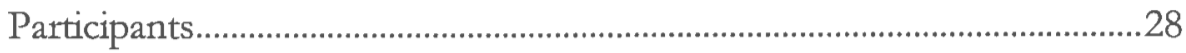

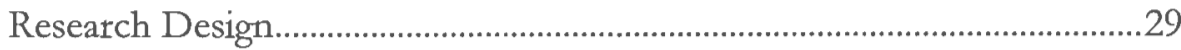


Study Variables

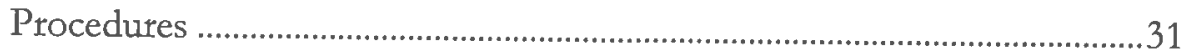

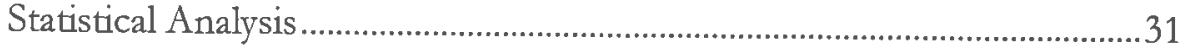

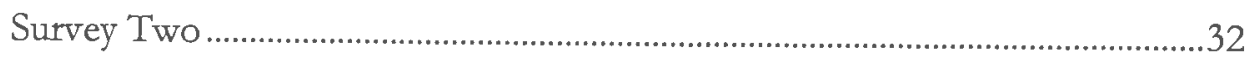

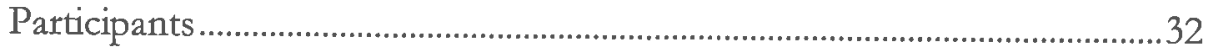

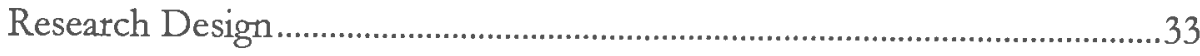

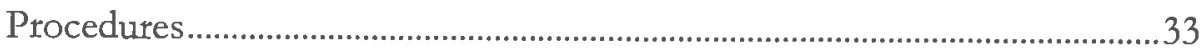

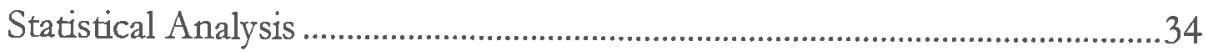

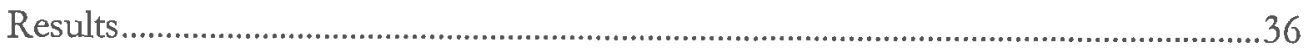

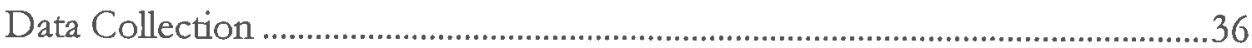

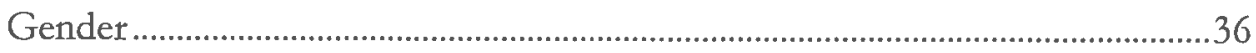

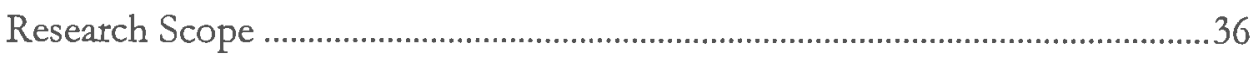

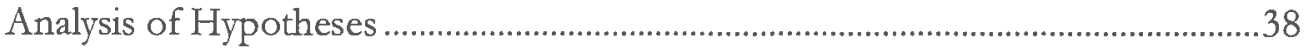

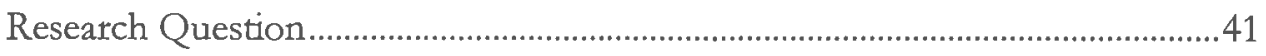

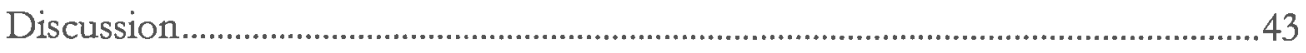

Strengths and Implications .................................................................................46

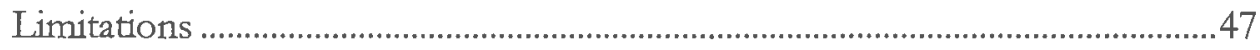

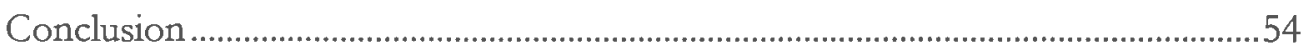

Appendix A: Source Credibility Survey ……………………….............................62

Appendix B: Source Credibility Survey (Female Employees) ....................................65

Appendix C: Source Credibility Survey (Male Employees) ........................................67 


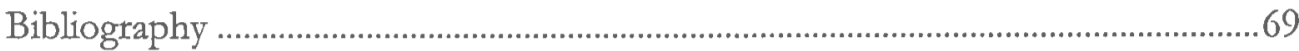




\section{List of Tables}

Table

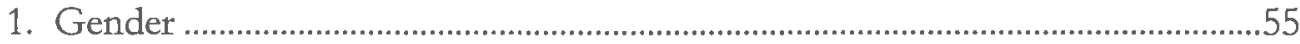

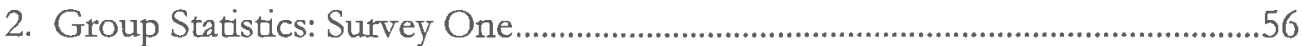

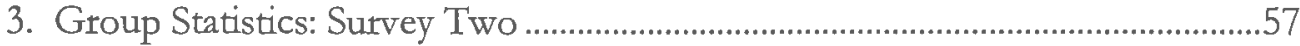

4. Chi-Square Tests: Quantitative Analysis of Advancement/Gender ..................58 


\section{List of Figures}

Figure

Page

1. Response to Research Question: First Ranked Barriers .........................................59

2. Response to Research Question: Second Ranked Bartiets ...................................60

3. Response to Research Question: Third Ranked Barriers ....................................61 
In today's global economy, successful leaders engage in and promote effective communication to advance a healthy organizational culture. Dynamic leaders realize successful communication is the effective exchange of information utilizing verbal and non-verbal channels resulting in a transmission of information, meaning and exerting influence. Effective communication within the work environment creates and maintains a business culture that cultivates a changing, diverse workforce and supports the mission and goals of the organization.

Effective leaders recognize the success of any organization is buttressed by specific elements, such as exemplary ethical standards and the integrity and credibility of its members. All individuals in an organization should be charged with maintaining these elements to manage the challenges of a competitive global economy.

I am especially intrigued by how credibility functions within an organizational culture. In particular, my interest rests on the relationship between gender and credibility. I propose an analysis of the credibility of women in male-dominated organizations. With respect to this study, a male-dominated organization is defined as an organization comprised of a greater proportion of men to women. In general, women across the United States are not advancing to positions of authority in maledominated organizations. I will explore the factors associated with the failure of women to advance to leadership positions, and in particular whether credibility plays a role. The central question with which I will be concerned is: do women possess less 
credibility than their male counterparts in a male-dominated organization and is credibility perceived to be a barrier to their advancement?

This proposal will review research pertinent to networking, credibility, advancement and gender in an organizational setting. In reviewing this literature, I will identify specific factors, such as elements of organizational dynamics and gender, which may impede women's credibility and advancement within an organization. Toward this end, I will construct a questionnaire grounded in the literature review to be administered to a sample of women and men representing a population of employees in a male-dominated organization. The purpose of this survey is to examine the role of gender in male-dominated organizations, especially regarding credibility, advancement and barriers to advancement.

This study is prompted by my desire to gain a greater understanding of organizational communication and the status of women in male-dominated organizations. For example, in the United States in 1997, "women workers were equally qualified vis-à-vis male workers, and they constituted 46 percent of the managerial workforce. In Canada, women in 1997 accounted for 42 percent of all managers. However, a 1996 survey of Fortune 500 companies showed that women held only 2.4 per cent of the highest management jobs and accounted for a tiny 1.9 per cent of the highest-paid officers and directors" (Catalyst, 1997, p 3).

In 2004, "women managers accounted for 45 percent of all managers, but women held fewer than 3 percent of the top management positions in Canada and 2.4 percent in the United States" (Helliwell, 2004, p. 4). While it seems relatively easy for women to gain employment at the lower levels of the organization, they are still under- 
represented in management positions as a whole, and it is proving very difficult for them to reach middle and senior management positions. "It is widely accepted that women are under-represented in positions of authority within the world of work" (White \& Cox, 1991, p. 19). Specifically, women are under-represented in maledominated organizations. For example, at Costco, a male-dominated organization, "women hold only one in six of the richly paying top management positions" (Morris, 2005, p. 642). Plus, "at a time when women make up 45 percent of the United States labor force, technology companies report that only 10 percent to 30 percent of their programmers, engineers and managers are women" (Wilen, 2000, p 5). At Walmart, it takes women longer to reach a management position and "the higher one looks in the organization, the lower the percentage of women. Walmart employs 1.2 million United States women, but only one-third of all managers and 14 percent of store managers are women" (Curry, 2004, p. 6). In addition, women are not a viable force on corporate boards of major corporations or male-dominated organizations.

For example, "four years ago, only 10 percent of corporate board positions were held by women with 150 of the Fortune 500 Companies reporting to women board members" (Goldstein, 2003, p. 14). In 2003, sixteen of the top 30 companies had at least one woman among the highest paid officers. Today, women account for only 8 percent of the nation's top-earning executives at Fortune 500 companies. This number represents improvement as women held just 1.2 percent of all top-paying corporate jobs in 1995, according to Catalyst, a New York-based advocacy group for women in business (Catalyst, 1998). The pendulum is moving very slowly in terms of women advancing to key positions in the workforce. 
Further, when women do find themselves in positions of organizational leadership, such as when they occupy management roles, often those positions are less strategic and in lower paying areas of the organization. Women do exert a vital influence throughout the United States economy but experience obstacles and challenges hindering their advancement. Additionally, isolated by their male counterparts, women often encounter organizational and cultural norms that ascribe credibility to men and not to women, which only undermines women's advancement in the workplace (Marshall, 1986).

Credibility is the foundation of leadership. "Of all the attributes of credibility, there is one that is unquestionably of greatest importance. Credibility has to do with reputation and is earned over time" (Peters, 1987, p. 627). A person's reputation in an organizational setting lies in the qualities of being honest, inspiring, competent, composed, and being perceived an expert; these qualities, incidentally, are the foundational characteristics of what communication researchers refer to as source credibility (McCroskey \& Young, 1981).

Although women are not generally found in management positions in a maledominated organization, most women embrace a management style that centers around communication and positive working relationships and is considered to be better suited than men's to the team-oriented leadership of today according to the Hayberg Consulting Group (Catalyst, 1998; Korabik \& Ridgeway, 2002; Powell, 1993). A study by Correll (2001) rated women superior to men in such traditional management skills as hiring, coaching and developing subordinates and organizing as well as 
monitoring others. Despite these skills, women do not advance to management positions at a rate representative of their numbers in the workforce.

Powell (1993) agrees that women find substantial deterrents to their advancement. Gender is an extremely salient stimulus characteristic that affects both the manner in which men and women perceive themselves and the way in which they are perceived as credible and evaluated by others. The selective perception and interpretation of information based on gender stereotyping can result in biases that are detrimental to women (Korabik \& Ridgeway, 2002). Obtaining the leader role may be problematic for women since the perceptions of a leader/manager are different than the perception of a woman. Thus, women may encounter challenges as they strive to advance in an organization and to achieve the perceptions of being credible.

Syvensky and Madden (1996) argue that even when women have the skills and abilities necessary to effectively lead in an organization, they may still have difficulty convincing others of their credibility, and so may not advance to positions of leadership. This lack of credibility occurs partly because of perceptions associated with women's feminine communication style. "Masculine and feminine stereotypes are quite different" (Bem, 1974, p. 156; Eagley \& Crowley, 1986, p. 239). The masculine stereotype depicts men as tough, aggressive, forceful, dominant, risk-takers, adventurous and able to endure pressure. Conversely, feminine stereotypes depict women as emotionally supportive, kind, compassionate, gentle, helpful and warm. "Studies have found masculine behaviors are more associated with successful management than feminine behavior" (Powell \& Butterfield, 1989, p. 216). Since masculine behaviors have been equated with being a successful manager and feminine 
behaviors have not, the feminine stereotype associated with women leads people to perceive that women have less power and ability than they actually have (Broverman, 1972) and may result in the perception that women are less qualified than men for high level management positions (Schein, 1973).

Interestingly, Oakley (2000) claims some women, in their efforts to accrue credibility, consciously select to downplay their own femininity in favor of a more "masculine" behavior associated with leadership success and credibility. Interestingly, it appears that research has resulted in identifying women's deficiencies and/or specific attributes that are not aligned with the male-dominated organizational culture (Oakley, 2000). In contrast, little research has been conducted to explore the positive contributions of females in the male-dominated organization. As Powell (1993) asserts, organizations need to re-establish and expand their notions of what constitutes effective leadership pertinent to gender, stereotyping and role expectations. 


\section{Review of the Literature}

A review of pertinent literature reveals several factors, such as credibility, organizational dynamics and gender, impact the status of women within the organizational hierarchy in male-dominated organizations. An explanation of these factors provides specific reasons for their inclusion in this study.

\section{Credibility}

According to Webster's Dictionary, the term credibility is synonymous with the words quality, capability or power to elicit a belief. A credible person demonstrates expertise in a specific area or field, consistently exhibits technical skills pertinent to his or her field of expertise and has the ability to impart change. Similarly, Tedeschi and Rosenfeld (1987) define credibility as the image or reputation of the individual attained through his or her expertise and reliability in past negotiation. Expertise is critical in order to be considered a credible source.

McCroskey and Young (1981) have provided the most informative and useful exposition on source credibility. McCroskey indicated that there are five dimensions of credibility: competence, character, sociability, extroversion and composure. According to McCroskey, an individual considered competent demonstrates a specific skill set and continuously strives to improve by engaging in professional development opportunities to stimulate his or her growth. An individual of character is also an individual who has integrity and ethical responsibility. McCroskey explains that sociability is an important attribute associated with credibility. An individual who develops networking skills and engages in social opportunities is considered to be likable and of a positive outlook. Credibility is associated with extroversion, a term 
used to define likable and persuasive individuals. It is highly likely that individuals who maintain their composure under stress or challenges will garner credibility.

A credible person has the ability to influence his or her audience to effect change. Putnam and Pacanowsky (1983), for example, claim there is evidence that managers may judge the validity of the information based on credibility of the source, not the facts of the matter. The acceptance of the information depends on whether the recipient perceives the sender to be credible. O'Reilly and Robert (1999) claim a particular component of the credibility construct may have the most impact on the audience. "The research on source credibility also suggests that it may be the "safeness" or trustworthiness of the source, more than the expertise, that determines whether information is believed" (O'Reilly \& Robert, 1999, p. 99). In addition to the believability of information, a high credibility source may also influence an audience on judgments of public presentation, attitude change and persuasion, and overall understanding of the message (Hovland, Janis \& Kelly, 1953; Lafferty \& Goldsmith, 1999; McCroskey \& Young, 1981).

In sum, then, credibility is a precursor to being perceived as an effective leader, persuader, and communicator generally. Indeed, it would appear then that credibility is a precursor to advancing within an organization, all other things being equal.

\section{Organizational Dynamics: Networking}

Highly credible communicators are, no doubt, afforded more social deference and have the privilege of joining wider social circles within which to develop relationships. Credible communicators are more likely to get their way more often than their less credible counterparts. While credibility is a much studied construct, an 
understanding of its impact in organizational settings has been lacking. Additionally, while we know relatively little about how credibility functions in an organization, we know even less about how it is constructed, and maintained. Said another way, we know very little of credibility's precursors. "The importance of understanding credibility formation becomes theoretically and socially necessary as persuasive communicators are often motivated by their individual desire to achieve specific objectives" (Miller, 1978, p. 33).

Generally, the importance of professional and personal relationships for development of credibility cannot be underestimated. The credible woman has developed specific behavioral patterns indicative of credibility: a successful track record, technical competence, demonstrated ethical behavior and building trust (Kanter, 1983). Developing relationships marked by trust (one of the components of credibility discussed earlier), however, is often difficult for some women in maledominated organizational settings due to their often limited interaction with male employees in networking and/or social opportunities.

Often, women encounter gender-related obstacles embedded within the structure of an organization that make it difficult for them to establish a perception of being trustworthy. Women, by definition, are distinct minorities in male-dominated organizations, and they are excluded frequently from developing a tacit understanding of organizational dynamics (Kanter, 1983). For example, it is not unusual for male employees to form after-work athletic leagues to which women usually are not invited. Participation in these athletic opportunities generates camaraderie, goodwill and an opportunity to develop trusting relationships among the participating male employees. 
Yet, certain male-oriented networking opportunities have been entrenched in the work environment and its cultural structure. Kanter (1983) claims that organizations and management systems were formed when the workforce consisted predominantly of males, both in leadership and non-leadership positions (see also Korabik \& Ridgeway, 2002). As a result, Kanter (1983) sees "the organizational structure as contributing to exacerbate and exploit gender differences" (Kanter, 1983, p. 1271).

Despite the advent of women into both the workforce and management, "there has been little fundamental change to the underlying culture" (Still, 1994, p. 4). In many cases, the inner circle of male senior-level executives and professionals have shared experiences, such as sporting activities, company boards and community and professional organizations. "A certain amount of "bonding" and trust builds up because of these opportunities" (Mann, 1995, p. 25). Participating in the inner circle results in trust, which fosters the perception of credibility.

However, non-participation in this inner circle may have implications for other components of credibility in addition to trust. For example, women may be passed by in favor of a male counterpart when task assignments are made. Women may be assigned tasks that give them little opportunity to showcase technical expertise and competence.

The question becomes how does a woman confront the hierarchical and cultural structure of the male-dominated organization so as to achieve the same level of credibility as her male counterparts? Women attempt to overcome bias as well as gain recognition and credibility by working to appear competent. Often, women 
achieve recognition resulting in credibility during organizational transitions, such as downsizing or the hiring of a new senior management person, who is receptive to redesigning and revamping the current structure. The reorganization of departments and functions within a company is the ideal opportunity for a woman to develop expertise, a component of credibility, through a broader understanding of specific technical and managerial functions and interrelationships to which she would not otherwise have had exposure.

In addition, women overcome bias by achieving specific goals under the direction of a mentor. With the guidance of a mentor, women are more likely to achieve specific goals yielding recognition for their competence and technical expertise. Technical expertise and competence are two of the dimensions described by McCroskey and Young (1981) as being necessary for advancement and being perceived as credible.

\section{Gender Beliefs and Stereotypes}

While there appears to be certain organizational structures that impede the formation of credibility in women, there are also wider social structures that may function in much the same way. Research has shown that gender can play a considerable role in the advancement and ascribed credibility of women (Ridgeway \& Correll, 2004). One of the important achievements in our knowledge about gender in the past decade is the revolution in our theoretical conceptualizations of what is gender. There is increasing consensus among gender scholars that gender is not primarily an identity or role that is taught in childhood and enacted in family relations. Additionally, gender is a system of social practices for constituting people as two 
significantly different categories - men and women - and organizing social relations of inequality on the basis of that difference (Ferree, Hess \& Lorber, 1999; Lorber, 1994; Nakano-Glenn, 1999; Ridgeway, 1997; Risman, 1998).

Like other multi-level systems of difference and inequality, such as those based on race or class, theorists claim that gender involves cultural beliefs and distributions of resources at the macro level, patterns of behavior and organizational practices at the interactional level and identities at the individual level. "Widely shared hegemonic cultural beliefs about gender and their effects in what we call social relational contexts are among the core competencies that maintain and change the gender system" (Ridgeway \& Correll, 2004, p. 511). If gender is a system for constituting difference and organizing inequality on the basis of that difference, the widely held cultural beliefs that define the distinguishing characteristics of men and women and how they are expected to behave clearly are a central component of that system. Cultural beliefs about gender are stereotypes, and they have a substantially broader significance from a political and socioeconomic perspective. Stereotypes regarding gender have the potential of labeling women to assume certain roles and tasks within our society and, specifically, within our work environment.

In addition, social relational contexts are of interest because the process of defining self in relation to others evokes hegemonic cultural beliefs regarding gender. "Studies show that widely held gender beliefs do exist in the United States" (Fiske, Lin \& Neuberg, 2002; Lueptow, Lueptow \& Garovich-Szabo, 2001). In general, stereotypes describe women as more communal and men as more instrumental (Eagley, Wood \& Dickman, 2000). Men are viewed as having more status and as 
being competent at the things that "count the most". Women are seen as less competent, in general, but "nicer" and better at communal tasks, even though these tasks themselves are less valued (Conway, Pizzmiglia \& Mount, 1996; Fiske, et al, 2002).

Some theorists, such as Loden (1985), claim that men and women embrace a masculine or feminine style of leadership. Loden (1985) claims that a masculine leadership style is synonymous with a quantitative approach to management. For example, a masculine leadership style focuses on market position, turnover and profitability. In contrast, a feminine leadership style measures success qualitatively, such as personal satisfaction and team building opportunities. A person who embraces a feminine leadership style is interested in developing group-based consensus. Clearly, there is a difference in these two styles.

Gender beliefs represent themselves as a societal depiction of women and men defined by a narrow set of features. What is important here is that men and women enter most social relational contexts expecting others to believe that men are generally more competent than women. People's sense of what others expect of them affects behavior and biases judgment (Correll, 2001; Ridgeway, 1997). In organizational contexts, gender becomes a basis for bias on the part of the employee and his or her colleagues in the way an individual performs the tasks associated with the role of manager, clerk or student rather than a coherent and independent set of behaviors in itself.

Research has shown that exactly the same performance or idea seems better to people when it comes from someone who is of higher status rather than lower status. 
Because "being male" occupies a higher position in the social hierarchy than "being female," when men and women perform similar tasks, men are likely to be judged as having more ability at the task than women (Correll, 2001). To be judged equally able, women may actually have to perform better than the men (Pugh \& Wahrman, 1983). To that end, Catalyst, Inc. of New York conducted a study, Closing the Gap: Women's Advancement in Corporate \& Professional Canada, identifying the two main factors that senior female managers credit for their success. One is doing what people expected, and the other is developing a style with which male managers are comfortable (Catalyst, 1997). If a male manager is comfortable with a woman's management style, it is likely that the woman will be accepted within the management circle. 


\section{Theoretical Perspectives}

I have explained the concept of credibility and examined possible reasons why women are diminished in developing credibility in an organizational setting. These reasons are grounded in organizational and broader social structures. In this section, I wish to examine theoretical frames against which to cast the relationship between gender and credibility in an organizational setting. Among the relevant theoretical frames are the social role theory and the structuration theory. In this section of the proposal, I will review both theories.

\section{Social Role Theory}

The social role theory stipulates that individual behavior is driven by societal expectations (Carless, 1998). Social role theory argues that any difference between men and women in an organizational setting can be accounted for by socialization of the individual male and females, each bringing their own set of gender expectations for themselves and their peers. Carless (1998) claims female leadership expectations include more of the behaviors and styles one would find in transformational leadership, which is collaborative and fosters teamwork and development of people. Women, in general, are more likely to exhibit skills fostering participative leadership and collaborative group management (Carless, 1998).

Male managers, on the other hand, are expected to demonstrate an authoritarian style (Johnson, 1995). Additionally, the male approach tends to be high risk, high gain because all other males in the environment are in the same competitive position (Johnson 1995). As a result, this perspective states that some males are more likely to 
embrace aggressive strategies. Males have a tendency to dominate, which is often seen in physical behavior, such as interrupting during conversations.

Cultural values guide expectations at the organizational level. For example, organizations in the United States are characterized by increased individualism and a clearly defined increased focus on individual achievement (Boatwright \& Forrest, 2000). If cultural values impact individual and group behaviors in an organizational setting, it is likely that these values will impact leadership behaviors and subordinate perception.

If the general cultural norm indicates that the preferred and expected leadership style is masculine (Ayman-Nolley, Ayman \& Becker,1993), men may be more likely than women to be perceived as credible and so advance in an organization. In other words, an organization may adopt social and organizational values and mores, which are accepted by similar organizations, in its attempts to define an incipient organizational culture or change an established one. Often, it is more convenient to mirror the established "good old boys" culture, and the norms associated with it, rather than deviate to create a unique culture. This appropriation of cultural gender expectations by an organization may result in organizational culture characteristics that are also gender specific.

"Research in both the laboratory and organizational settings has indicated that when physical characteristics, such as gender are novel, they can become salient and influence observed participation in a stereotypical manner" (Kanter, 1977, p. 965). Team members are likely to perceive men in leadership positions matching gender role expectations. In comparison, "female leaders are often faced with team members who 
may hold discrepant expectations about the role of a leader and a women's gender role" (Korabik \& Ridgeway, 2002, p. 227; see also Ayman-Nolley, Ayman \& Becker, 1993). Thus, in order to be successful, women will exhibit a leadership style that conforms to the cultural expectations of what is appropriate leadership behavior; in many cases this will be the stereotypically "masculine" style of leadership.

Lorenzen (1996) claims that one's professional competence, credibility and personal history are integrated with the roles and personnel within an organization. The perception of leadership effectiveness along gender lines is defined by personal, social and cultural characteristics. "When women undertake a leadership role, they bring into the role their gender, the culturally defined female aspects, as an integrated part of their personal history and their profession" (Lorenzen, 1996, p. 26). It appears that female behaviors involve more person-oriented leadership styles. Some theorists claim that this style does not match the expectations of what a leader should be in a male-dominated organization. According to Freeman (1993), women then adopt a more masculine behavior.

Research has shown that successful managers are perceived to be very similar to men and not to women, despite the feminist movement (Loden, 1985). At the same time, female managers face normative pressures to behave "feminine" (Cialdini $\&$ Trost, 1998). This balancing can impact the well-being of female managers and make it more difficult for women to reach the top (Kanter, 1983; Powell, 1993). Earning the trust of followers, colleagues and supervisors requires developing and using tact and relationship skills and enacting them within the context of organizational norms. 
In most organizations dominated by males, it is likely that employees will function within an autocratic framework because of the nature of the creation and appropriation of cultural norms and values by those organizations. The autocratic style is perpetuated as organizations cling to societal expectations. According to the social role theory, there are certain expectations likely to be in force in a male-dominated organization. These expectations are likely to value the male autocratic leadership style rather than female leadership styles. Consequently, women may be perceived as less credible than men if they do not use an autocratic style. Women may even consider assuming a masculine/autocratic leadership style in order to be perceived as credible and effective leaders in a male-dominated organization.

A second theory that lends itself to gaining an understanding of the interplay between gender, credibility and leadership is the structuration theory. This theory emphasizes that specific structures are produced, accepted and eventually integrated within the organizational dynamics.

\section{Structuration Theory}

The structuration theory is appealing when studying the credibility of women in male-dominated organizations; the theory reflects classic concepts of an organization, particularly with respect to organizational structure and organizational climate. "Part of the appeal of the structuration theory is that structures are embedded in the dynamics of specific groups, organizations or institutions, and can be viewed as a dynamic process with characteristics of both stability and change" (Poole \& DeSanctis, 1992, p. 37). The stucturation theory is useful for understanding how people, as active agents, produce and reproduce the structures of social systems" 
(Miller, 2002). Members of an organization conform to and duplicate specific structures in order to maintain the synergy of the organizational culture. In addition, the structuration theory indicates that structures are salient to organizational members and are reproduced in social interaction situations. This statement is important; both men and women in an organization often recognize the roles in a structure, which is embedded in the organizational culture and guides the expectations of organizational members. According to Salazar (1996), roles are produced and reproduced by group members through the application of rules and resources. Because structures are produced and sustained within an organizational culture, perceptions of credibility in the male-dominated culture are accepted and integrated within the framework of the organization.

The brainchild of sociologist Anthony Giddens, the structuration theory is a social action theory, which claims that human action is a process of producing and reproducing social systems. Communicators act strategically according to established rules to achieve goals and, at the same time, create structures that affect future actions (Miller, 2002). These structures guide individuals' actions. Interestingly, individual actions in turn create new rules/structures. Our social life relies on structures in order for individuals to accomplish tasks. Critical to our understanding of the structuration theory is that structures are created, maintained and changed as a result of our interactions with other people.

In thinking about the credibility of women in male-dominated organizations, certain structures are endorsed by the established hierarchical landscape that encourage and allow certain individuals to demonstrate their expertise, technical skills and 
knowledge. Often, those occupying the upper echelons of the hierarchical landscape are predominantly men (Valian, 1998). If an organization is predominantly male, it is likely that men will be perceived as credible and likely to succeed in advancing to management or leadership positions. As a result, the structures created promote the perception that men are more credible in comparison to women. Since women are the minority in a male-dominated organization, it is unlikely that the created structure will enable women, in general, to demonstrate their expertise and specific skills. For example, Schein (1973) argues that one major barrier impeding the progress of women may be the sex typing of the managerial job: think manager, think male. "Greater barriers to women's advancement often exist in male-dominated contexts in which the norms have been set by men, who make up the majority group (Korabik \& Ridgeway, 2002, p. 27). While some women attempt to ensure effective decisions are made through particular gender qualities, such as emphasizing care and concern, these attempts are often seen as organizational stereotypes. Yet, Salazar (1996) reminds us that the androgynous person is likely to perform both female and male behaviors depending, of course, on the specific situation. This statement is important and will be discussed in the Summary of Theoretical Research.

In addition to stereotypes, organizational rules and norms are key terms when discussing the structuration theory. "Social life must be considered in terms of both structure and agents. Structures are the rules, norms and beliefs that characterize the social world" (Miller, 2002, p. 65). Agents are the individuals who sustain the established structure. These agents are responsible for maintaining the structure to avoid conflict or adversity. An important element in the structuration theory is that the 
relationship between structure and agents should be defined in terms of duality of structure. Structures are produced by human agents, but these structures are the medium through which agents operate.

Conversely, it is important to note that while a structure enables interaction, it may also constrain actions within a specific dynamic (Miller, 2002). Additionally, agents have the ability to influence the structure in which they function (Miller, 2002). There are situations where rules of the game and balance of power are constantly shifting. "The stability of a social system is largely determined by internal relations among various layers of structure" (Putnam \& Pacanowsky, 1983, p.173). It is important to note that the structuration theory distinguishes systems and structures, as the structures are the rules and resources people use in interaction (Poole \& McPhee, 1983). Critical to the structure, systems are elements that affect one another within an environment and are integral to sustaining the established structure (Littlejohn, 2002).

According to Salazar (1996), structures sustain as long as they are part of the social interaction process. In thinking about small-group dynamics, structures guide individuals in terms of acceptable and appropriate behavior. As a result, group members have an expectation regarding the behavior to be performed. "A person's behavior is then enabled and conditioned by the structures he or she draws on" (Salazar, 1996, p. 492). By invoking rules, members are reproducing and perpetuating the established norms and mores of an organization. Members rely on the norms and mores of an organization to provide direction and guidance regarding how they are to interact in the organizational landscape 
Summary of Theoretical Research

Theoretical evidence has been presented to support the claim that women in male-dominated organizations are perceived as less credible in comparison to their male peers. The social role theory claims that organizational members use expectations in guiding their behavior; these expectations, generally, but especially in a male-dominated work setting, tend to devalue women. The structuration theory claims organizational members use structures to guide their interactions, and emphasize how structures are created and maintained. In male-dominated organizations, a structure of hierarchy develops or is appropriated on the basis of gender, which precludes the development of women's credibility.

In addition, the same research reveals that women in male-dominated organizations are often slow to realize advancement given their lack of power and perceived limited credibility by their peers. While women demonstrate technical competence and expertise, they are excluded from many informal relationships and social events which provide significant opportunities for building networks and developing trust among peers. Developing trust is key to being perceived as a credible individual. Participating in these social circles or networks is critical in order for women to break into male-dominated networking systems and to be perceived as credible.

Interestingly, most women's management style, in comparison to the style of most men, centers around communication and positive working relationships. Women typically display exemplary social skills, effective communication styles, and putting the success of the team first and use influencing skills rather than authority to get 
things done (Lorenzen, 1996). These tendencies and skills are better suited to the team-oriented leadership of today. Yet, women continue to be challenged by the authoritative leadership styles preferred by most males and which are prevalent and accepted by most organizations. The power structure in most organizations continues to remain male oriented, despite the growing number of women in the workforce. Yet, I foresee some areas to be explored concerning women, credibility and advancement. In particular, I question how leadership skills defined as being female in style, such as collaborative and teamwork-oriented, can be integrated within the organizational dynamics of the male-dominated organization.

\section{Summary}

To summarize the theoretical stance: the social role theory claims that individual behavior is driven by societal expectations. Organizations appropriate and adopt these societal expectations, in their creation of organizational culture, which then becomes normative. These organizational norms, in male-dominated organizations, tend to guide behavior along gender lines. Additionally, they favor the emergence of male leaders, and result in male leaders being evaluated (ascribed credibility) more favorably then female leaders. Usually, the preferred management style of men is based on an autocratic approach focusing on driving organizational goals. As a result structures have been developed creating an opportunity for men to achieve their goals based on an autocratic style. Females tend to be interpersonally oriented and utilize a participative leadership style. However, female managers may opt to embrace an autocratic style to be considered credible given the established structures within the male-dominated organization. A woman may suppress her 
interpersonal style of leadership in an organization numerically dominated by men in order to maintain her authority and position.

In particular, the structuration theory addresses the classic concepts of an organization, especially with respect to organizational structure and organizational climate. Members of an organization embrace specific structures and rules in order to maintain the synergy of the organizational culture. Since structures are produced and sustained within an organizational culture, the perceptions of credibility in the maledominated culture are accepted and integrated within the framework of the organization.

In summary, the structuration theory is critical to this study, as structures are reproduced in social interaction situations allowing organizational members to leverage situations to advance the organizational synergy. A masculine stereotype depicts men as aggressive, risk takers and dominant. Conversely, women are stereotypically depicted as emotionally supportive, kind, compassionate and gentle. Studies have shown that masculine behavior is more associated with successful management than is a feminine management style. Since masculine behavior is associated with a successful management style, a perception is created that women are less qualified than men for upper management-level positions. Often, women opt to downplay stereotypically feminine qualities in favor of a masculine behavior style associated with leadership, success and credibility. Yet, an androgynous person is capable of performing masculine and feminine behavior to meet the needs of the situation. This concept is interesting, particularly with respect to the structuration theory. "The development of a new group structure may sometimes occur whenever 
groups are faced with new situations and really do not have a template or recipe for proceeding" (Salazar, 1996, p. 490). The androgynous person is capable of responding to the situation by appropriately reacting with male or female behavioral patterns.

Plus, gender can play a role in the advancement and credibility of women. Gender is a system of identifying people as two significantly different categories: male and female. Gender is a system for organizing inequality stereotypes assuming men and women embrace certain roles and traits within society. Therefore, men are viewed as having more status and being competent at the tasks that count the most. Structures have been created in organizational dynamics recognizing that a similar performance or idea seems better when coming from someone of higher status. Since males occupy a higher status in the social hierarchy, men are more likely to be judged as having more ability at the task than women. It is important to note that the structuration theory emphasizes that individuals employ a set of rules to coordinate their interactions with each other in a situation. Since men and women recognize the organizational structures, the perception of credibility in a male-dominated culture is accepted and integrated within the framework.

In addition to the literature reviewed, the social role theory and the structuration theory lead to the hypotheses and research question. 


\section{Hypotheses}

1. Women, compared to their male peers in a male-dominated organization, are perceived as less credible.

2. A smaller proportion of women will be in management positions when compared to men in a male-dominated organization.

\section{Research Question}

1. Is lack of credibility among the major barriers to advancement women encounter in a male-dominated organization? 


\section{Methodology}

\section{Introduction}

I conducted two (2) surveys to investigate the credibility of women in a maledominated organization. The population from which I compiled a sample comprises employees of a male-dominated organization known as Consumer Value Store, otherwise known as CVS. In existence for more than 40 years, CVS has more than 5,000 stores in 36 states, 13 distribution centers, regional business offices, and its Store Support Center in Woonsocket, Rhode Island. CVS was ideal for my research as it is a major corporation composed of a male-dominated workforce and is currently experiencing rapid economic growth. Specifically, I conducted a survey in the Store Support Center, a division of CVS, located in Woonsocket, Rhode Island. A hub of activity, the Store Support Center comprises seven (7) departments whose function is to support the 44 retail stores located throughout Rhode Island. The following departments are part of the Store Support Center: Administration, Customer Care, CVS Realty Center (comprising Finance and Treasury), Human Resources, Information Technology, Marketing and Plant Operations.

Recognized as the largest pharmacy retailer in Rhode Island, CVS employs approximately 2,000 employees in the Store Support Center facility. The majority of CVS employees in Rhode Island are located in the Store Support Center since seven departments function from this facility to support the 44 retail stores in Rhode Island. These retail stores in Rhode Island employ approximately 1,000 employees. Of the 2,000 employees in the Store Support Center, approximately 60 percent are men and 
approximately 40 percent are women. Therefore, the Store Support Center in Woonsocket employs approximately 1,200 men and approximately 800 women. Survey 1:

Participants

I randomly distributed as hard copy an anonymous survey to $1 / 2$ of female employees and $1 / 2$ of male employees within the CVS Realty Center, one of seven divisions of the CVS facility located at Cumberland Hill Road. The CVS Realty Center comprises the Finance and Treasury Departments, with 240 employees. The proportion of men to women in the Woonsocket office is approximately 3-to-2 (60-to40 percent). This study included 120 employees: 72 males and 48 females. Officials with whom I had contact at CVS selected the Realty Center employees to participate in the survey, as the physical design of the department and its workflow were conducive to allowing employees to participate in a survey. The primary functions of the CVS Realty Center include the collections of bad debts (mainly bad checks and credit card fraud); restructuring of credit with banks as rates fluctuate; auditing of store construction costs; monitoring and litigating of ad valorem (property) tax; creating and monitoring budget lines for property tax, construction, utilities, credit cards, and insurance; and lease administration for both stores and warehouses.

I distributed the survey to a cross section of employees in the CVS Realty Center. I solicited input from exempt and non-exempt employees (i.e. employees in management and non-management positions, respectively). By using a random selection method, the demographics of the participants varied in terms of gender, educational level attained, number of years employed by CVS, and the employee's 
position in the company, yet still represented the demographic characteristics of the organizational departments being studied.

Research Design

The study is a correlational design in which the individual is the unit of analysis. A survey utilizing the McCroskey Source Credibility Scale was distributed to study participants.

Study Variables

This study examined the following pertinent variables: competence, character, sociability, extroversion and composure. McCroskey and Young (1981) identified these attributes as making up the source credibility construct.

Competence is defined as the ability to demonstrate specific skills, knowledge and abilities in a consistent manner. A competent person is capable of functioning independently to provide accurate and timely information utilizing appropriate communication vehicles. A person with character is a unique or extraordinary individual of a specific rank or capacity who exhibits notable traits, such as a moral quality and strength of mind to resolve situations in an independent manner. Sociability is defined as the desire and ability to understand situations so as to get along with people to foster goodwill and camaraderie. Extroversion is defined as an interest in or behavior directed toward others or one's environment rather than oneself. Extroversion is a trait that emerges as the individual enters situations, such as meeting people, resolving a challenge or conflict. Associated with the word "stable," composure is defined as remaining calm and poised in difficult or challenging 
situations. Composure is a skill and is developed over time by exhibiting thoughtful responses to people and situations.

Study Variable 1: The variable of gender was assessed through participants indicating if they are male or female. (See Part A, Item 1 in Appendix A)

Study Variable 2: The level of advancement achieved by the employee (i.e. Vice President, Director, non-management employee) responding to the survey was identified on the survey. (See Part A, Item 2 in Appendix A).

Study Variables 3,4,5,6,7: Participant's level of competence, sociability, extroversion, composure and character was measured using the McCroskey Source Credibility Scale (1981). (See questions 1-15 in Appendix A: Questions 1-3 pertain to sociability; Questions 4-6 pertain to Extroversion; Questions 7-9 pertain to Competence; Questions 10-12 pertain to Composure and Questions 13-15 pertain to Character).

Research Question: I also asked participants to rank order the barriers they perceived to advancement. The responses allowed me to gain additional data to support my hypotheses. Specifically, the data provided by these participants allowed me to gain an understanding of the possible barriers to advancement to a management or leadership position experienced by women in a male-dominated organization. Provided by male and female participants, the data enriched my research findings and specifically provided me with insight about barriers to advancement. Finally, this data was useful to me as I formulated a conclusion pertinent to my hypotheses. (See Part C in Appendix A) 


\section{Procedures}

I personally distributed an anonymous survey to $1 / 2$ of female and male employees of the Finance and Treasury Departments of CVS Realty Center in the Woonsocket office. This distribution yielded 120 participants to take part in this study. I distributed a survey to every other employee in the Finance and Treasury Departments starting with the first desk in the Finance Department. The desks are sequentially numbered, and there is one employee per desk. By selecting every other desk, I selected $50 \%$ of the employees of the CVS Realty Center to form the sample for my study. I was not provided with the names of the employees in order to maintain their anonymity and confidentiality.

The survey was distributed to each participant with a return envelope addressed to me. A cover sheet was included pursuant to the Institutional Review Board Guidelines. In addition, I explained to the participants that I am enrolled in the Communication Studies Program at URI and am working on my master's thesis.

I asked all participants to return the survey to me within 10 calendar days. Follow-up notices were sent seven calendar days after the initial survey mail-out. I encouraged the participants to contact me if they had any questions, concerns or if they did not want to participate in the survey. I provided the participants with a broad overview of my study.

\section{Statistical Analysis}

The results of this survey allowed me to test my hypotheses: 1) Women in a male-dominated organization will be perceived as less credible in comparison to their male peers; 2) A smaller proportion of women will be in management positions when 
compared to men in a male-dominated organization. I analyzed the responses of the participants to answer the research question: Is lack of credibility among the major barriers to advancement women encounter in a male-dominated organization? The data pertinent to the research question is presented on a bar graph revealing the barriers to advancement selected by this sample. An analysis of hypothesis one was conducted using a t-test of group means for males and females with regard to each of the five characteristics (competence, character, sociability, extroversion and composure) as well as a composite measure (overall credibility) of the McCroskey \& Young (1981) Source Credibility Scale (Appendix A). An analysis of hypothesis two was conducted using the chi square test. Answering the research question was done by examining the top barriers identified by women as they attempt to advance to positions of greater power within the organization.

Survey 2 :

\section{Participants}

I personally distributed Survey Two, an anonymous survey, to the fourteen (14) managers employed by the CVS Realty Center in the Woonsocket office in order to test Hypothesis One with regard to the credibility of women in male-dominated departments. The fourteen (14) managers did not receive Survey One. There are eight (8) managers in Finance and six (6) managers in Treasury, the departments making up the Realty Center. The Director of Treasury provided me with an alphabetical list of the names of the fourteen (14) managers in the Finance and Treasury Departments. This list could not leave the CVS facility in Woonsocket. 
These managers were randomly assigned to receive questionnaires that asked them to assess the credibility characteristics of their immediate male or female subordinates. Seven managers from the alphabetical list received a questionnaire designed to assess their male employees. Seven (7) managers received a questionnaire designed to assess their female subordinates. The specific questions that the managers were asked on which to assess their employees are presented in Appendix B (for assessment of female employees) and Appendix C (for assessment of male employees).

\section{Research Design}

This portion of the thesis examined the managers' perceptions of the credibility of female and male employees: competence, character, sociability, extroversion and composure, and overall credibility. The difference between this phase of the thesis and the previous one is that managers only were selected, and they made assessments of their immediate male or female employees on only five items (see Appendix B and C). One item was selected from McCroskey and Young's (1981) scale to measure each of the five elements of credibility identified above. The number of items was shortened so as not to impose on the managers' time. I selected these items on the basis of the best representation of the underlying concept. As well, the managers may have been sensitive to some of the items, and so I elected to not include these items in the list.

\section{Procedures}

I personally distributed an anonymous survey to all fourteen (14) managers within the CVS Realty Center of the Store Support Center. I solicited assistance from 
the Director of Treasury at the CVS Realty Center who provided me with an alphabetical list of the names of the managers in the Treasury and Finance Departments. The Store Support Center of CVS, to include the CVS Realty Center, represents a male-dominated organization. I distributed a survey to all managers of the CVS Realty Center to participate in the survey. This method allowed me to obtain a representative sample of managers at the Store Support Center. There are 126 managers at the Store Support Center, and there are fourteen (14) managers in the CVS Realty Center. The proportion of male to female managers in the Woonsocket office is approximately 7 -to-3 (70-to-30 percent).

The survey was hand delivered to each participant with a return envelope addressed to me. A cover sheet was included pursuant to the Institutional Review Board Guidelines. In addition, I explained to the participants that I am enrolled in the Communication Studies Program at URI and am working on my master's thesis.

I asked all participants to return the survey to me within 10 calendar days. Follow-up notices were mailed seven days after the initial mail-out. I encouraged the participants to contact me if they have any questions, concerns or if they did not want to participate in the survey. I provided the participants with a broad overview of my study.

Statistical Analysis

The results of this survey provided, in addition to Survey One, data to test my first hypothesis: 1) Women in male dominated organizations will be perceived as less credible in comparison to their male peers. Specific items were selected from the McCroskey Source Credibility Scale (Appendix B) for the survey. I analyzed the 
responses of the managers pertinent to McCroskey's five elements of credibility: competence, character, sociability, extroversion and composure. In addition, I composed a composite measure of credibility using the five elements from the McCroskey Source Credibility Scale. The mean score of the managers' assessments of their male subordinates was compared to the mean managers' assessments of their female subordinates using a t-test. This data determined if the managers' perceptions of male and female employees differ with regard to credibility in male-dominated organizations. 


\section{Results}

This section will analyze the results of the statistical analyses intended to test the two proposed hypotheses and answer the research question. As well, I will discuss the return rates and gender distribution of the respondents and the scope of research.

\section{Data Collection}

Data was collected through two surveys distributed to various employees of the CVS Realty Center. Of the 120 total surveys distributed, 111 were completed and returned. A total of 106 participants received Survey One, and a total of 14 participants received Survey Two. Of the 111 surveys, 97 participants responded to Survey One. A total of 14 managers responded to Survey Two (see Table 1). Gender

Of the 97 participants completing Survey One (see Table 1), 38 percent were completed by females $(n=37)$ and 62 percent were completed by males $(n=60)$. Sixty-four percent of the respondents to Survey Two (see Table 1) were male, and 36 percent were female.

Research Scope

The purpose of my research was to conduct a theoretical analysis of the perception of women as credible leaders in a male-dominated organization. My goal was to explore the gender differences in credibility and identify the factors associated with the failure of women to advance to leadership positions in a male-dominated organization, and in particular, whether credibility plays any role. To satisfy this goal, two hypotheses and one research question were formulated. 
The Pearson product moment correlation coefficient was computed to test hypothesis one and a chi square test was used to test hypothesis two. I utilized a .05 significance level. The Statistical Package for the Social Science (SPSS) was utilized to conduct the statistical analysis. 
Hypothesis 1: Women, compared to their male peers in a male-dominated organization, are perceived as less credible.

According to the t-tests conducted, Table 2 shows that there is no significant difference between women and men in any of the credibility measures from both employees' and managers' perspectives (see Table 3). Therefore, Hypothesis One is rejected.

In Survey One, respondents were asked to judge how they thought their immediate supervisor perceived them with regard to overall credibility and its various subcomponents. In looking at the data from the employees in response to Survey One, the mean scores for male and female employees are very close. Specifically, the mean scores for overall credibility for male and female participants is 2.44 and 2.45 , respectively (see Table 2).

With respect to sociability, female employees have a mean score of 1.96 while male employees have a mean score of 2.09 , a non-significant difference $(t=.624 ; \mathrm{df}=$ $95 ; p=.53$; see Table 2 ). Both male and female participants responded similarly to extroversion with males having a mean score of 2.80 and females having a mean score of 2.96. This difference was not significant $(t=-.531 ; \mathrm{df}=95 ; \mathrm{p}=.60$; see Table 2$)$. With respect to competence, male and female participants scored similarly with mean scores of 2.30 for males and 2.58 for females $(t=1.45$; $d f=95 ; t=.15$; see Table 2$)$.

The mean scores for composure for male and female participants is 3.02 and 3.01 , respectively. In terms of composure, there is no significant difference in the response of the participants $(t=.028 ; \mathrm{df}=95 ; \mathrm{p}=.98$; see Table 2$)$. Finally, in terms 
of character, male and female participants scored similarly with mean scores of 1.96 and 1.74 for males and females, respectively $(t=1.01 ; \mathrm{df}=95 ; \mathrm{p}=.32$; see Table 2$)$.

To study the managers' perceptions of their male and female employees regarding credibility, Survey Two was distributed to the fourteen managers of the CVS Realty Center. A total of fourteen managers participated in the survey: seven male and seven female. In reviewing the data, the mean score for overall credibility is 2.34 for male managers and 2.86 for female managers. The results indicate there is no significant difference in the managers' perceptions of the overall credibility associated with male and female employees $(t=1.71 ; d f=12 ; p=.11$; see Table 3$)$.

In addition, each of the five items that comprise the overall credibility measure were analyzed for differences between males and females. Those components were: good natured/irritable; verbal/quiet; expert/non-expert; poised/nervous and sympathetic/unsympathetic. In terms of good natured/irritable, the mean score for male employees is 2.14 and 2.29 for female employees. The results tell us that there is no significant difference in the managers' perceptions of these traits associated with their male and female employees $(t=-.264 ; \mathrm{df}=12 ; \mathrm{p}=.80$; see Table 3$)$.

With regard to verbal/quiet, the mean score for male employees is 2.00 and 2.29 for female employees. There is no significant difference between male and female employees with respect to this component. $(t=1.00 ; \mathrm{df}=12 ; \mathrm{p}=.34$; see Table 3).

In terms of expert/non-expert, the mean score for male employees is 2.58 , and the mean score for female employees is 3.29 . There is no significant difference 
$(t=-.804 ; \mathrm{df}=12 ; \mathrm{p}=.44 ;$ see Table 3$)$. Likewise, regarding poised/nervous, the mean score male employees is 2.00 , and the mean score for female employees is 3.43 . The data reveals a significant difference in the managers' perceptions of these male and female employees regarding poised and nervous $(t=2.09 ; \mathrm{df}=12 ; \mathrm{p}=.06$; see Table 3).

Lastly, the perceptions of the managers are similar regarding the characteristics of sympathetic/unsympathetic. Both male and female employees have a mean score of 3.00. Therefore, the data tells us there is no significant difference in the manager' perception of male and female employees regarding this component $(t=.000 ; \mathrm{df}=12$; $\mathrm{p}=1.00$; see Table 3 ).

Hypothesis 2: A smaller proportion of women will be in management positions when compared to men in a male-dominated organization.

Table 4 shows that there is no significant difference between the proportion of women who were in management positions when compared to men in management positions in this male-dominated organization. Hence, Hypothesis Two is rejected.

Men and women in management positions appear to be represented in direct proportion to their representation in this male-dominated organization. The results tell us there is no significant difference in the proportion of male and female managers in this organization (chi square $=.991 ; \mathrm{df}=1 ; \mathrm{p}=.32$; see Table 4 ). This study quantitatively illustrates that advancement is not dependent on gender in this maledominated organization. 


\section{Research Question}

Question: Is lack of credibility among the major barriers to advancement women encounter in a male-dominated organization?

Male and female participants identified common themes regarding barriers to advancement. Participants were asked to rank what they perceived as the top three barriers to advancement. The top three barriers most frequently ranked first were inexperience, limited power and not aggressive enough (see Figure 1). The three barriers most frequently ranked second were limited power, leadership skills and not aggressive enough (see Figure 2). Interestingly, there is an overlap in this category from the first ranked barrier. The three barriers most frequently ranked third were limited power in present role, inexperience and not aggressive enough (see Figure 3).

In addition to ranking specific barriers, participants had the opportunity to identify "other" barriers hindering their personal advancement. Response to the "other" category revealed that male and female employees felt that lack of mentoring programs is a hindrance to advancement. Both male and female employees included lack of networking situations in the "other" category.

Also in the "other" category, two of the 44 female participants revealed that family responsibilities limit the time they can devote to putting in the extra hours often necessary to advance. In addition, three of the 44 female employees commented that going to school in the evening most definitely limited their time to spend at work, which only hindered their chance for advancement at this juncture. A total of three female employees indicated that lack of a college degree was definitely an obstacle. 
Plus, three women indicated that lack of work-related experience was perceived as an obstacle.

The survey also reveals specific data, which I had not encountered in my bibliographic research. Specifically, female and male participants indicated that race was an obstacle in term of advancement. Specifically, two of the 67 male participants commented that being a young black male was perceived, in their opinion, to be an obstacle. Likewise, one female employee commented that being a Persian female under 30 was definitely an obstacle she would need to manage. 


\section{Discussion}

Central to this study was the integration of two theories, namely the structuration and the social role theory. This study focuses on organizational communication, in particular, and source credibility within a male-dominated organization. The structuration theory was particularly useful as it is pertinent to how structures are produced and reproduced within social systems. The structuration theory analyzes how structures are created, maintained and how structures change as a result of actions. Incorporating this theory in my study was helpful as it allowed me to understand that structures are embedded in the dynamics of an organization. Therefore, individuals in an organization act a certain way based on organizational mores and rules that are embedded within the organizational dynamics. Individuals in a specific dynamic have an expectation regarding the behaviors to be performed; this behavior is enabled by the structure. However, a new structure may develop resulting in a situation unfamiliar to group members. Of significance, it is the androgynous person who is capable of responding with specific male or female skills to meet the challenges of the unfamiliar situation.

Specifically, I applied the concepts of this theory in studying gender, the credibility of women in a male-dominated organization and the obstacles women encounter in their attempt to advance. Structures (McPhee, 1985) result in a set of rules specific to that social system, which are identifiable to members of the organization. Critical to this study were the inclusion of credibility and gender despite the rejection of the hypotheses. The research on source credibility (O'Reilly \& Robert, 
1999) indicates it may be the safeness or trustworthiness of the source in comparison to the expertise of the person determining whether information is believed. A message delivered by a communicator is positively influenced by specific qualities of the communicator, such as affection, admiration, fear and awe. According to O'Reilly and Robert (1999), a credible person can influence his or her audience. In addition, McCroskey andYoung (1981) revealed that an important factor influencing the effectiveness of a communicator is the person or group perceived as originating the communication and the cues provided as to the trustworthiness, intentions and affiliations of the source.

Secondly, the social role theory stipulates that individual behavior is driven by societal expectations (Carless, 1998). This theory supports the claim that barriers to advancement exist in male-dominated contexts where norms have been set by men who comprise the majority. Research (Sheriff, 1994) has revealed that norms are long lasting, and it can take several generations before they are questioned. Even as the number of women in male-dominated organizations increases, a change of culture and/or organizational dynamics will evolve rather than occurring immediately.

As Sheriff (1994) claims, it will take time to alter presently accepted organizational norms. Possibly, the organizational mores of the CVS Realty Center may have paled the participants' candid response to this survey. For example, CVS is a service-oriented industry and most likely is representative of the philosophy typical of a service-oriented industry. Employees in a service-oriented environment are encouraged to embrace a customer service philosophy, which tends to result in a 
positive experience in the work environment for employees. As a result, employees' perceptions of their supervisor and work environment may be more favorable.

Though the survey results do not support my hypotheses, the social role theory speaks to the fact that behavior is driven by societal expectations. Just as women encounter challenges in their attempts to be perceived as credible, women face societal norms preventing them from moving forward within the male-dominated organization. With that said, the social role theory would lead one to expect that women at the CVS Realty Center would not advance in proportionate numbers to their male peers. Yet, women employed at the CVS Realty Center are advancing in proportionate numbers to the men employed at the CVS Realty Center. The advancement of women and their ascribed credibility may be attributed to the service-oriented work environment of this organization. I found both theories were useful in advancing this study despite the hypotheses being rejected.

Critical to sustaining credibility is the development of and participation in networking opportunities. The importance of professional and personal relationships for developing credibility cannot be underestimated. Yet, women encounter genderrelated obstacles embedded in organizational structures, which make it very difficult to establish a perception of being trustworthy. A male-oriented networking opportunity is entrenched in the work environment creating yet one more obstacle for women in their attempt to advance. As Kanter (1983) stresses, organizational structures exploit gender differences making it difficult for women to participate in activities that are part of the process to advance. For example, women are often not invited to afterhour athletic leagues or a game of golf. According to the survey results, women are 
often not taken seriously and sometimes excluded from work-related activities where vital information is shared. Yet, at the CVS Realty Center, credibility was ascribed proportionately to women and men. Plus, women did advance in numbers proportionate to their representation in the organization.

My bibliographic research revealed that men and women enter most social relational situations expecting others to believe that men are generally more competent than women. It is obvious that gender is critical to this study as hegemonic cultural beliefs about gender (Ridgeway \& Correll, 2004) and their effects are among the core competencies that maintain and change the gender system. To be judged equally, women often have to perform better in order to be recognized by their supervisor and peers. Though the survey results did not support this statement, research did reveal that gender plays a role in the perception of credibility ascribed to women and advancement to leadership positions.

\section{Strengths and Implications}

Though I did not find support for these two hypotheses, this study should be considered meaningful and of value. This study examined the credibility associated with women in comparison to men. Plus, this study examined the advancement of women to management positions in a male-dominated organization and the challenges encountered by women in their attempt to advance. The responses to the research question revealed an array of barriers women and men encounter in their quest for advancement. However, the barriers do not have a great impact because we do see a proportionate amount of men and women at the CVS Realty Center advancing to management positions. Specifically, two of the 67 male participants indicated that 
race was a barrier. Likewise, one out of 44 females indicated being a female Persian under the age of 30 was a barrier. Two out of 44 females indicated that family responsibilities were considered a barrier. The barriers identified were minimal prohibiting me from gaining a wide variety of data to the research question.

\section{Limitations}

While this study proved to be a positive experience for me personally, I recognize that certain limitations exist. Some of those limitations include the venue for the survey and design of the survey.

Specifically, it was challenging to locate a venue willing to accommodate my request to conduct a survey. Fortunately, CVS was amenable and directed me to the CVS Realty Center. While this venue was acceptable, I question whether a larger sample set at CVS would have been more helpful. For example, the CVS Realty Center comprises 240 employees, and the questionnaires were distributed to half of the employees resulting 120 participants. Although I received an overwhelming response with a return rate of 111 respondents, the mean scores are very close. In retrospect, it would have been helpful if CVS had allowed me to distribute the survey to several departments so that I would have had a larger sample set comprised of a more diverse population, i.e. participants of various ages, educational background and race.

Likewise, I was limited to distributing Survey Two to the fourteen managers of the CVS Realty Center. It would have been helpful to solicit input from a larger sample set. By referring to Table 3, it is obvious that the data from the managers is not significant and is limiting to my study. Unfortunately, I was limited to the CVS Realty Center, a department of CVS. 
Possibly, the design of the survey was a hindrance. It would have been helpful if more participants had provided examples of obstacles encountered regarding advancement. A thought to consider: If the research question had been formulated differently, would the participants have been more receptive to providing input? For example, the research question asked: In your opinion, what barriers do you encounter in your attempt to advance to a management or leadership position in a large organization? Possibly, some participants did not answer this question because it was not applicable. Specifically, if individuals are not interested in pursuing a management position, then they may not answer this question. It is possible that the design of the question alienated some participants for that very reason. Rather, a possible option for the question could have been: If you were considering advancement to a management or leadership position in a large organization, what barriers do you anticipate encountering? Redesigning the research question is something to consider for a future study. With 111 responses to the survey, I should have seen more responses to the research question.

Yet, it is important to discuss the common barriers to advancement identified by the participants. As previously mentioned, the top three barriers are inexperience, not aggressive enough and limited power in my present role. The number one barrier is inexperience, which is a common response by men and women pursuing advancement to a management position.

I would like to focus on the correlation between inexperience and the narrow discrepancy in credibility perceived by men and women of the CVS Realty Center. If men and women identify inexperience as a common barrier, then it is seems 
understandable that both men and women will share similar perceptions of their respective credibility. In addition, the participants indicated that limited power is another barrier. Having limited power in a role can be detrimental to imparting credibility and conveying competence. Perceiving oneself as having limited power may impede an employee from pursuing personal and professional development opportunities within the work environment. Also, an employee convinced that they possess limited power may be likely to refrain from developing specific skills, such as networking skills, in order to advance. As research continues pertinent to credibility and gender, these barriers could be considered for integration within the realm of future studies.

In terms of the survey variables, I would reevaluate the use of the variables for a future survey. For example, it is speculation as to whether the participants had difficulty relating to some of the variables, such as identifying whether their manager perceives the employee as intellectual versus narrow. Also, individuals may perceive the variables "poised" versus "nervous" as being awkward. For example, some men may feel uncomfortable identifying themselves as "poised," as that has somewhat of a feminine connotation. However, it is important to note the reliability of this scale.

If I were to conduct the survey again, I would consider the following options:

1) Secure an organization amenable to providing me with a larger sample set.

Possibly, a larger sample set would provide me with more poweer to detect siginificant differences in hypothesis testing; 2) Conduct interviews with a specific sample set so that I could glean additional data, particularly with respects to obstacles; 3) Consider a technology-oriented industry rather than a service-oriented industry. Possibly, a 
sample set at a technology-oriented industry would have been more representative of a male-dominated philosophy. Despite the technology boom, women continue to fall behind men in terms of employment and advancement (Guido, 2003). Women continue to assume positions as office workers in comparison to managers or engineers. For this reason, a study at a technology-oriented organization would have been appealing and appropriate for this study.

I was surprised at the insignificant difference concerning the perception of credibility ascribed to female employees in a male-dominated organization. I would have thought there would have been a more significant difference in responses provided by the male and female participants. A thought: could it be that times are changing, and there really is not a significant difference in the credibility ascribed to male and female employees?

I would like to reflect on that question. The article, "At CVS There Are No Limits on How Far Anyone Can Go", provided me with valuable insight as to the cultural dynamics of this male-dominated organization. According to Pierette Kelly (2005), vice president of CVS.com, women employees are encouraged to provide feedback and suggestions and certainly bring a new dimension to management decisions and discussions. In order to meet competitive challenges, CVS is representative of a diverse work environment. Board member Sheli Rosenberg claims, "gender and ethnic diversity are crucial to meeting the demands of a varied customer base" (Pinto, 2005, p. 3). Of significance, one goal of Tom Ryan, President and CEO of CVS in Rhode Island, is to significantly expand the number of women in top CVS management positions. Ryan's goal is coming to fruition when taking a second look at 
the CVS Realty Center with fourteen managers, seven of whom are women. This is an interesting point as there are an equal number of men and women managers in this specific department. Yet, CVS is clearly a male-dominated organization and is representative of a service-related industry. However, the study conducted at this specific venue concludes that men and women are advancing proportionately. In addition, this study reveals that credibility is ascribed to both men and women.

Although the survey results do not support my hypotheses, the results lead me to believe that women and men at the CVS Realty Center are advancing and are perceived as credible managers. While the momentum for advancement, in general, may be slow, the evolution of women as credible managers is occurring and will continue. This statement is important, as women and men need mentors in their quest for personal and professional development.

With seven female managers at the CVS Realty Center, both men and women employees have an opportunity to engage in positive mentoring opportunities. In the ideal world, seven male and female managers create a unique balance of leadership skills and style resulting in an innovative environment, if fostered by the Vice President and Director. I think the equal number of female and male managers speaks volumes as to the importance of advancement at the CVS Realty Center and at CVS as an organization.

In addition, the equal number of male and female managers reflects a change in the structure of the department. Ideally, hierarchical structures prevalent in maledominated organizations may be lessened by the equal balance of female and male managers. With that said, employees of the CVS Realty Center should realize that 
advancement is possible. As a result, male and female employees, especially female employees, have the opportunity to advance and to be perceived as credible given their accomplishments and skill set.

As I reflect on this study, I realize my assumptions concerning the credibility of women in a male-dominated organization may be incorrect. For example, women who left large corporations for start-up companies have experienced the opportunity to advance (Guido, 2003). In traditional corporate environments, women were usually found in core areas, such as marketing, sales and manufacturing. Unfortunately, women were often disqualified for consideration for promotion attributed to their present role. Conversely, women in high-tech firms experienced a positive work culture to include: day care possibilities and job sharing where employees share the tasks of one specific role. "The internet boom lowered the barriers for women to enter the high-tech industry because the technical requirements were hardware-driven", according to Denise Brousseau, founder of Forum 5 Enterpreneurs (Guido, 2003, p. 3). In newer industries, like technology, "it's strictly qualifications that get you where you want to go", according to David Puhr, CEO of DP Parker \& Associates. The cultural dynamics of the high-tech world appear to be somewhat different than some of the traditional industries, such as insurance. Specifically, "high tech companies' short development cycles and cut throat culture have helped women succeed. In a pressure cooker environment, executive are judged on whether they meet sales and marketing goals and not on who their gold buddies are", (Black, 2003, p. 2). In fact, some companies, such as Hewlett Packard and Xerox have clearly defined performancemanagement systems which result in a systemic approach beneficial to women. 
Interestingly, high-tech companies tend to offer salaries based on previous compensation so that the more you made before the move to a high-tech company, the more you earn when accepting a position (Messmer, 2003). With that said, compensation packages in the high-tech industry appear to be based on a different philosophy than the traditional corporate environment.

Yet, "the barriers and demands of the high-tech industry are very similar to those of the traditional industry", according to Catalyst President Ilene Lang. "What is surprising is that both women and men perceive a lack of acceptance, as companies do not strategically and objectively identify and develop talent" (Guido, 2003, p. 4). As a result, the challenge to advance in a high-tech industry is now experienced by both men and women. This phenomenon is new both men and women. Often, the challenge to advance in a traditional or male-dominated organization was experienced by the female employee, rather than the male employee. For these reasons, my assumption regarding the credibility of women in a male dominated organization and their barriers to advancement may be incorrect. 


\section{Conclusion}

The purpose of this study was to conduct an analysis of women and credibility in male-dominated organizations. Specifically, I explored the factors associated with the failure of women to advance to leadership positions, and in particular whether credibility plays a role. My research revolved around gender, credibility and advancement in organizational settings. My analyses revealed that no difference exists between the perception of credibility associated with women and the credibility ascribed to men in one male-dominated organization. In addition, this study revealed that there is no significant difference in the proportion of males and females in management positions. Holding a management position does not appear to be dependent on gender.

While no significant results were obtained, this study identified an array of barriers encountered by women and men in their attempts to advance in a maledominated organization. These barriers, such as race and lack of strategic mentoring programs, are designated obstacles to advancement. Future research should concentrate on the development and implementation of mentoring programs to propel men and women forward in their quest for advancement. As women strive to advance in a male-dominated organization, the opportunity to participate in a mentoring program will provide exposure to specific leadership and management skills necessary for advancement. 
Table 1

Gender

Response to Survey One Response to Survey Two

Male

60

9

Female

37

5

Total

97

14 
Table 2

Group Statistics: Survey One (Distributed to 97 participants)

\begin{tabular}{llllllll}
\hline & Gender & $\mathrm{N}$ & Mean & $\mathrm{sd}$ & $\mathrm{t}$ & $\mathrm{df}$ & $\mathrm{p}$ \\
Overall Credibility & Male & 60 & 2.44 & .804 & -.073 & 95 & .94 \\
& Female & 37 & 2.45 & .821 & & & \\
Sociability & Male & 60 & 2.09 & 1.048 & .624 & 95 & .53 \\
& Female & 37 & 1.96 & 1.106 & & & \\
Extroversion & Male & 60 & 2.80 & 1.480 & -.531 & 95 & .60 \\
& Female & 37 & 2.96 & 1.248 & & & \\
Competent & Male & 60 & 2.30 & .895 & 1.45 & 95 & .15 \\
& Female & 37 & 2.58 & .945 & & & \\
Composure & Male & 60 & 3.02 & 1.353 & .028 & 95 & .98 \\
& Female & 37 & 3.01 & 1.236 & & & \\
Character & Male & 60 & 1.96 & 1.067 & 1.01 & 95 & .32 \\
& Female & 37 & 1.74 & 1.045 & & & \\
\hline
\end{tabular}

* Note: Lower numbers are indicative of greater credibility. 
Table 3

Group Statistics: Survey Two (Distributed to 14 Managers)

\begin{tabular}{|c|c|c|c|c|c|c|c|}
\hline & Gender & $\mathrm{N}$ & Mean & sd & $\mathrm{t}$ & $\mathrm{df}$ & $\mathrm{p}$ \\
\hline Overall Credibility & $\begin{array}{l}\text { Male } \\
\text { Female }\end{array}$ & $\begin{array}{l}7 \\
7\end{array}$ & $\begin{array}{l}2.34 \\
2.86\end{array}$ & $\begin{array}{l}.690 \\
.395\end{array}$ & 1.71 & 12 & .11 \\
\hline $\begin{array}{l}\text { Good natured/ } \\
\text { irritable }\end{array}$ & $\begin{array}{l}\text { Male } \\
\text { Female }\end{array}$ & $\begin{array}{l}7 \\
7\end{array}$ & $\begin{array}{l}2.14 \\
2.29\end{array}$ & $\begin{array}{r}1.345 \\
.488\end{array}$ & -.264 & 12 & .80 \\
\hline Verbal/quiet & $\begin{array}{l}\text { Male } \\
\text { Female }\end{array}$ & $\begin{array}{l}7 \\
7\end{array}$ & $\begin{array}{l}2.00 \\
2.29\end{array}$ & $\begin{array}{l}.000 \\
.756\end{array}$ & 1.00 & 12 & .34 \\
\hline $\begin{array}{l}\text { Expert/ } \\
\text { Non-expert }\end{array}$ & $\begin{array}{l}\text { Male } \\
\text { Female }\end{array}$ & $\begin{array}{l}7 \\
7\end{array}$ & $\begin{array}{l}2.58 \\
3.29\end{array}$ & $\begin{array}{l}1.718 \\
1.604\end{array}$ & -.805 & 12 & .44 \\
\hline $\begin{array}{l}\text { Poised/ } \\
\text { Nervous }\end{array}$ & $\begin{array}{l}\text { Male } \\
\text { Female }\end{array}$ & $\begin{array}{l}7 \\
7\end{array}$ & $\begin{array}{l}2.00 \\
3.43\end{array}$ & $\begin{array}{l}1.000 \\
1.512\end{array}$ & 2.09 & 12 & .06 \\
\hline $\begin{array}{l}\text { Sympathetic/ } \\
\text { Unsympathetic }\end{array}$ & $\begin{array}{l}\text { Male } \\
\text { Female }\end{array}$ & $\begin{array}{l}7 \\
7\end{array}$ & $\begin{array}{l}3.00 \\
3.00\end{array}$ & $\begin{array}{l}1.290 \\
1.826\end{array}$ & .000 & 12 & 1.00 \\
\hline
\end{tabular}

* Note: Lower numbers are indicative of greater credibility. 
Table 4

Chi-Square Tests: Quantitative Analysis of Advancement/Gender

\begin{tabular}{lccc}
\hline & Value & df & Asymp Sig. 2 sided \\
Pearson Chi-Square & .991 & 1 & .32 \\
$\mathrm{~N}$ & 97 & & \\
\hline
\end{tabular}


First Ranked Barriers

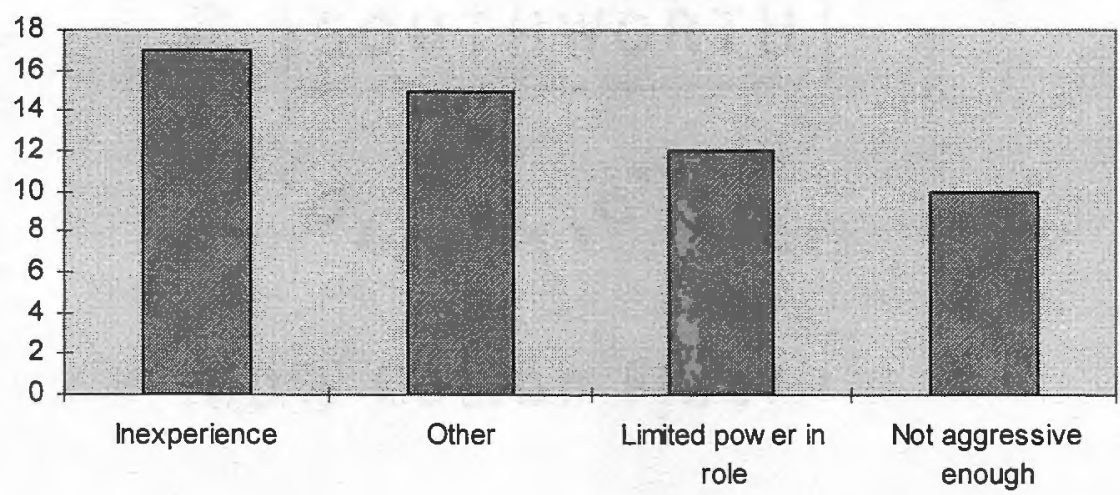

Figure 1

Response to Research Question: First Ranked Barriers 


\section{Second Ranked Barriers}

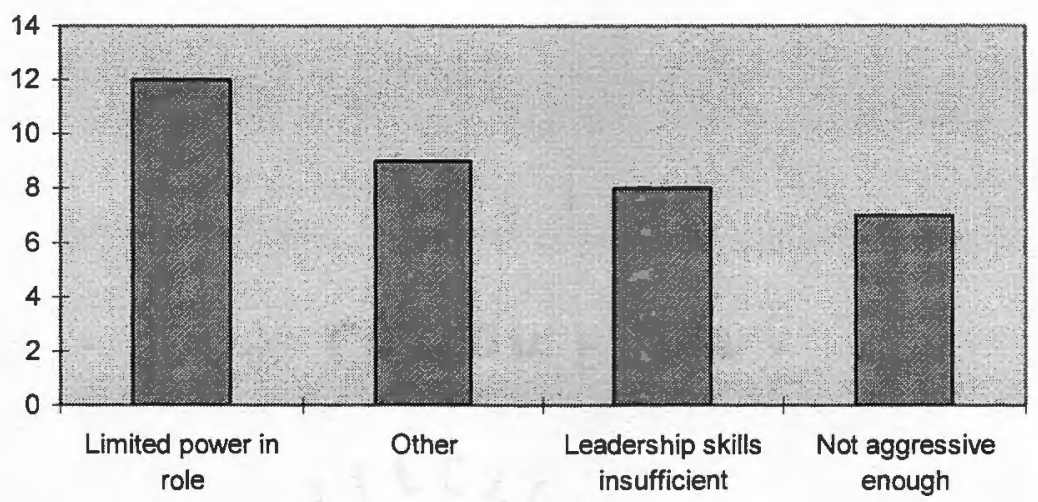

Figure 2

Response to Research Question: Second Ranked Barriers 


\section{Third Ranked Barriers}

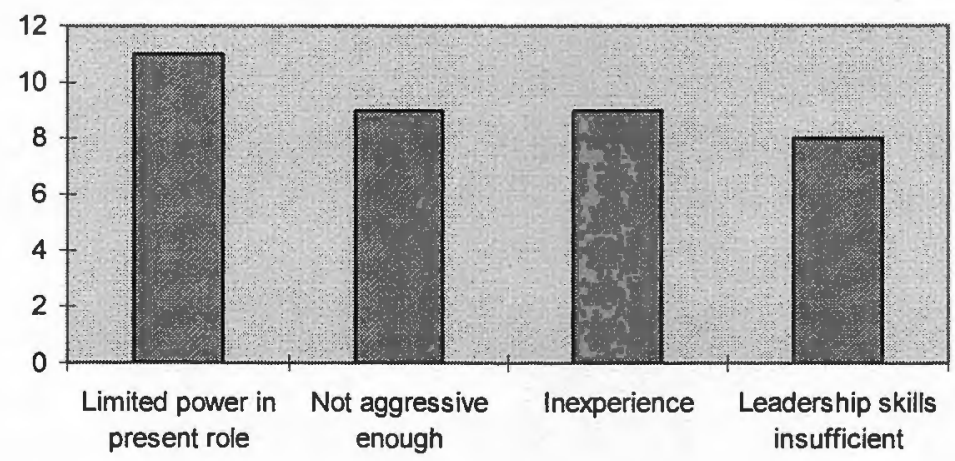

Figure 3

Response to Research Question: Third Ranked Barriers 


\section{Appendix A}

You have been selected to participate in a confidential survey to assist me with my thesis preparation. I am enrolled in the Communication Studies Program at URI and would appreciate receiving your input to be used as part of my research.

Specifically, I am interested in leadership attributes of individuals in large organizations. If you wish to provide additional input for any of the questions, please use the space provided.

Thank you for completing this confidential survey. Please return this survey questionnaire to me no later than April 25, 2005 in the enclosed envelope.

Thanks,

Regina Bell

Part A

1. Please identify your gender.

Male Female

2. Are you in a management position?

Yes No

3. If you answered "yes" to question 2 above, would you describe your position as Vice President

Director

Manager

Supervisor

Other 
Part B

On the scales below, indicate how you think your manager or supervisor feels about you as an employee. Circle the number between the adjectives which best represents your feelings about how you think your manager feels about you, as am employee. Numbers " 1 " and "7" indicate a very strong feeling. Numbers "2" and "6" indicate a strong feeling. Numbers " 3 " and " 5 " indicate a fairly weak feeling. Number "4" indicates you are undecided. There are no right or wrong answers.

$\begin{array}{lllllllll}\text { 1.Good natured } & 1 & 2 & 3 & 4 & 5 & 6 & 7 & \text { Irritable }\end{array}$

$\begin{array}{lllllllll}\text { 2.Cheerful } & 1 & 2 & 3 & 4 & 5 & 6 & 7 & \text { Gloomy }\end{array}$

$\begin{array}{lllllllll}\text { 3.Unfriendly } & 1 & 2 & 3 & 4 & 5 & 6 & 7 & \text { Friendly }\end{array}$

$\begin{array}{llllllllll}\text { 4.Timid } & 1 & 2 & 3 & 4 & 5 & 6 & 7 & \text { Bold }\end{array}$

$\begin{array}{lllllllll}5 . \text { Verbal } & 1 & 2 & 3 & 4 & 5 & 6 & 7 & \text { Quiet }\end{array}$

$\begin{array}{lllllllll}\text { 6. Talkative } & 1 & 2 & 3 & 4 & 5 & 6 & 7 & \text { Silent }\end{array}$

$\begin{array}{lllllllll}\text { 7. Expert } & 1 & 2 & 3 & 4 & 5 & 6 & 7 & \text { Non-expert }\end{array}$

$\begin{array}{llllllllll}\text { 8. Not competent } & 1 & 2 & 3 & 4 & 5 & 5 & 7 & \text { Competent }\end{array}$

$\begin{array}{lllllllll}\text { 9. Intellectual } & 1 & 2 & 3 & 4 & 5 & 6 & 7 & \text { Narrow }\end{array}$

$\begin{array}{llllllllll}\text { 10.Poised } & 1 & 2 & 3 & 4 & 5 & 6 & 7 & \text { Nervous }\end{array}$

$\begin{array}{lllllllll}\text { 11. Tense } & 1 & 2 & 3 & 4 & 5 & 6 & 7 & \text { Relaxed }\end{array}$

$\begin{array}{lllllllll}\text { 12.Calm } & 1 & 2 & 3 & 4 & 5 & 6 & 7 & \text { Anxious }\end{array}$

$\begin{array}{llllllllll}\text { 13.Dishonest } & 1 & 2 & 3 & 4 & 5 & 6 & 7 & \text { Honest }\end{array}$

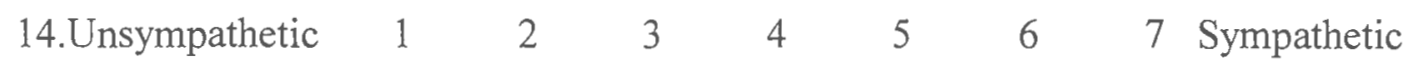

$\begin{array}{lllllllll}\text { 15.Good } & 1 & 2 & 3 & 4 & 5 & 6 & 7 & \mathrm{Bad}\end{array}$


Part C

1. In your opinion, what barriers do you encounter in your attempt to advance to a management or leadership position in a large organization?

Please rank the top 3:

(If you find that there are other important barriers, please specify in the blank space below. How would you rank the barriers you added to the list?)

Inexperience
Limited technical expertise in specific field
Credibility
Persuasiveness
Limited power in present role
Leadership skills perceived as insufficient
Not aggressive enough
Perceived inability to maintain composure in stressful situations
Perceived inability to lead employees
Inability to act logically in a crisis situation
Family responsibilities and expectations
Other (Please explain below)

Additional Comments: 


\section{Appendix B}

You have been selected to participate in a confidential survey to assist me with my thesis preparation. I am enrolled in the Communication Studies Program at URI and would appreciate receiving your input to be used as part of my research.

Specifically, I am interested in leadership attributes of individuals in large organizations. If you wish to provide additional input for any of the questions, please use the space provided.

Thank you for completing this confidential survey. Please return this survey questionnaire to me no later than April 25, 2005 in the enclosed envelope.

Thanks, Regina Bell

Part A

1. Please identify your gender

Male Female

2. As a member of the Management Team, please describe your position:

Director

Manager

Supervisor

Part B

On the scales below, please think about the female employees in your immediate supervision. Please circle the number that best describes your perception of these employees. Numbers " 1 " and " 7 " indicate a very strong feeling. Numbers "2" 
and "6" indicate a strong feeling. Numbers " 3 " and " 5 " indicate a fairly weak feeling. Number " 4 " indicates you are undecided. There are no right or wrong answers.

$\begin{array}{lllllllll}\text { 1. Good natured } & 1 & 2 & 3 & 4 & 5 & 6 & 7 & \text { Irritable }\end{array}$

$\begin{array}{llllllllll}\text { 2. Verbal } & 1 & 2 & 3 & 4 & 5 & 6 & 7 & \text { Quiet }\end{array}$

$\begin{array}{lllllllll}\text { 3. Expert } & 1 & 2 & 3 & 4 & 5 & 6 & 7 & \text { Non-expert }\end{array}$

$\begin{array}{llllllllll}\text { 4. Poised } & 1 & 2 & 3 & 4 & 5 & 6 & 7 & \text { Nervous }\end{array}$

$\begin{array}{lllllllll}\text { 5. Unsympathetic } & 1 & 2 & 3 & 4 & 5 & 6 & 7 & \text { Sympathetic }\end{array}$

Additional Comments: 


\section{Appendix C}

You have been selected to participate in a confidential survey to assist me with my thesis preparation. I am enrolled in the Communication Studies Program at URI and would appreciate receiving your input to be used as part of my research.

Specifically, I am interested in leadership attributes individuals in large organizations. If you wish to provide additional input for any of the questions, please use the space provided.

Thank you for completing this confidential survey. Please return this survey questionnaire to me no later than April 25, 2005 in the enclosed envelope.

Thanks,

Regina Bell

Part A

1. Please identify your gender

Male Female

2. As a member of the Management Team, please describe your position:

Director
Manager
Supervisor

Part B

On the scales below, please think about the male employees in your immediate supervision. Please circle the number that best describes your perception of these employees. Numbers " 1 " and " 7 " indicate a very strong feeling. Numbers " 2 " and 
" 6 " indicate a strong feeling. Numbers " 3 " and " 5 " indicate a fairly weak feeling.

Number "4" indicates you are undecided. There are no right or wrong answers.

$\begin{array}{lllllllll}\text { 1. Good natured } & 1 & 2 & 3 & 4 & 5 & 6 & 7 & \text { Irritable }\end{array}$

$\begin{array}{lllllllll}\text { 2. Verbal } & 1 & 2 & 3 & 4 & 5 & 6 & 7 & \text { Quiet }\end{array}$

$\begin{array}{llllllllll}\text { 3. Expert } & 1 & 2 & 3 & 4 & 5 & 6 & 7 & \text { Non-expert }\end{array}$

$\begin{array}{lllllllll}\text { 4. Poised } & 1 & 2 & 3 & 4 & 5 & 6 & 7 & \text { Nervous }\end{array}$

$\begin{array}{lllllllll}\text { 5. Unsympathetic } & 1 & 2 & 3 & 4 & 5 & 6 & 7 & \text { Sympathetic }\end{array}$

Additional Comments: 


\section{Bibliography}

Ayman-Nolley, S., \& Ayman, R., \& Becker, J. (1993). Gender affects children's drawings of a leader. Paper presented at the meeting of the American Psychological Society, Chicago, IL.

Bem, S. (1974). The measurement of psychological androgyny. Journal of Consulting and Clinical Psychology, 42, 155-162.

Black, J. (2003). The women of tech. Retrieved January 17, 2005 from www.Businessweek.com/technology/context/tc20030529_2635-5c111.htm..

Boatwright, K.J., \& Forrest, L. (2000). Leadership preferences: The influence of gender and needs for connection on workers' ideal preferences for leadership behaviors. Journal of Leadership Studies, 7 (2), 18-20.

Broverman, I. (1972). Sex role stereotypes: A current appraisal. Journal of Social Issues, 28, (59-78).

Carless, S. A. (1998). Gender differences in transformational leadership: An examination of superior leader and subordinate perspectives. Sex Roles, 39, 887902.

Catalyst. (1998). Census of women corporate officers \& top earners. (Issue No. v, 28cm). New York: Catalyst, Inc.

Catalyst. (1997). Closing the gap: Women's advancement in corporate and professional Canada. (Book 24, p: iii, $22 \mathrm{~cm}$ ). Ottawa: Conference Board of Canada: Gerkovich-Griffin, P., MacBride-King, J., \& Townsend, B. 
Cialdini, R., \& Trost, M. (1998). Social influence: Social norms, conformity, and compliance. In D. T. Gilbert, S. Fiske, \& G. Lindzey (Eds.), The Handbook of Social Psychology (14 ${ }^{\text {th }}$ ed.). (pp. 151-192). Boston, MA: McGraw-Hill.

Conway, M., Pizzamiglio, M., \& Mount, L. (1996). Status, communality and agency: Implications for stereotypes of gender and other groups. Journal of Personality and Social Psychology, 71, 25-38.

Correll, S. (2001). Gender and the career choice process: The role of biased selfassessments. American Journal of Sociology, 106, 1691-1730.

Curry, M. (2004). Walmart class action gender discrimination case holds warnings for all employees. Retrieved June 8, 2005 from www.business-markting.com/ store/article-walmart.html.

Eagley A., \& Crowley, M. (1986). Gender and helping behavior: A meta-analytic review of the social psychology literature. Psychology Bulletin, 100 (3), 238-308. Eagley, A., Wood, W., \& Dickman, A. (2000). Social role theory of sex differences and similarities: A current appraisal. In T. Eckes \& H. Tautner (Eds.), The developmental psychology of gender, 3, (pp. 140-151). Mahwah, NJ: Lawrence Erlbaum.

Ferree, M., Hess, B., \& Lorber, J. (1999). Introduction. In M. Ferrer, B. Hess \& J. Lorber (Eds.), Revisioning gender (pp. 5-9). Thousand Oaks, CA: Sage.

Fielden S., \& Cooper, C. (2001). Women managers and stress: A critical analysis. Equal Opportunities Interaction, 20 (2), 4-7. 
Fiske, S., Lin, M., \& Neuberg, S. (2002). The continuum model: Ten years later. In S. Chaiken \& Y. Trope (Eds.), Dual process theories in social psychology (pp. 61-73). New York: Guilford.

Freeman, S. (1997). The impact of gender differences on communication within a small business environment. Unpublished MSc dissertation, The Management School, University of Salford.

Goldstein, S. (2003). Women of influence. The Psychology of Persuasion, 16 (49), $14-18$.

Guido, M. (2003). Women lose ground in the tech field. Retrieved June 8, 2005 from www.mercurynews.com/mld/mercurynews/5184884.htm.

Hart, R. (1994). Critical Questions. New York: St. Martin Press.

Helliwell, T. (2004). Women's success at work. Retrieved May 26, 2005 from www.iitransform.com/newsletter archive/articleMar04.html.

Hovland, C., Janis, I., \& Kelly, H. (1953). Communication and persuasion. New Haven: Yale University Press.

Johnson, G. (1995). Monkey business - Why the way you manage is a million years out of date. London: Gower Publishing.

Kanter, R. (1977). Some effects of proportions on group life: Skewed sex ratios and responses to token women. American Journal of Sociology, 82, 965-990.

Kanter, R. (1983). Women and the structure of organizations. New York: Free Press.

Korabik, K., \& Ridgeway, J. (2002). Discrepancies in self/subordinates' perceptions of leadership behavior: leader's gender, organizational context, and leader's self- 
monitoring. Group \& Organizational Management, 27, (2) 29-56. Thousand Oaks, CA: Sage.

Lafferty, B., \& Goldsmith, R. (1999). Corporate credibility's role in consumer's attitudes and purchase intentions when a high versus a low credibility endorser is used in the ad. Journal of Business Research, 44, 109-116.

Littlejohn, S. (2002). Theories of human communication. Belmont, CA: Wadsworth Group.

Loden, M. (1985). Feminine leadership: Or how to succeed in business without being one of the boys. New York: Times Books.

Lorber, J. (1994). Paradoxes of gender. New Haven, CT: Yale University Press. Lorenzen, Z. (1996). Female leadership: Some personal and professional reflections. Leadership and Organizational Development Journal, 17 (6), 24-31.

Lueptow, L., Lueptow, M., \& Garovich-Szabo, L. (2001). Social change and the persistence of sex typing: 1974-1977. Social Forces, 80, 1-36.

Mann, S. (1995). Politics and power in organizations: Why women lose out. Leadership \& Organization Development Journal, 16 (2), 25-30.

Marshall, J. (1986). Women managers: Travelers in a male world. New York, NY: Wiley \& Sons.

McCroskey, J., \& Young, T. (1981). Ethos and credibility: The construct and its measurement after three decades. Central States Speech Journal, 32, 24-34. McPhee, R. (1985). Formal structure and organizational communication. In R. McPhee \& P. Tompkins (Eds.), Organizational communication: Traditional themes and new dimensions (pp. 88-136). Beverly Hills, CA: Sage Publishing. 
Messmer, E. (2003). Female IT professionals cope in a male-dominated industry. Retrieved January 17, 2005 from www.nwfusion.com/ news/2003/0929women.html.

Miller, G. (1978). Messages and message exchange process. In C. Berger and S. Chaffee (Eds.), Handbook of communication science (pp. 33-57). Newbury Park, CA: Sage Publishing.

Miller, K. (2002). Communication theories: perspectives, processes and contexts. Boston, MA: McGraw-Hill.

Morris, B. (2005). How corporate America is betraying women. Fortune, 151 (1) 6469.

Nakano-Glenn, E. (1999). The social construction and institutionalization of gender and race: An integrative framework. In M. Ferree, J. Lorber \& B. Hess (Eds.), Revisioning gender (pp. 129-125). Thousand Oaks, CA: Sage Publishing.

Oakley, C. (2000). Gender and formal authority. Social Psychology Quarterly, 56, 193-210. New York: Basic Books.

O'Reilly, C., \& Robert, K. (1999). Relationships among components of credibility and communication behaviors in work units. Journal of Applied Psychology, 61, 99102.

Peters, T. (1987). Thriving on chaos. Handbook for a management revolution. CA: Excel.

Pinto, D. (2005). At CVS there are no limits on how far anyone can go. Chain Drug Review, 27, (7), 3-22. 
Poole, M., \& DeSanctis, G. (1992). Microlevel structuration in computer-supported group decision making. Human Communication Research, 19, 5-49.

Poole, M., \& McPhee, R. (1983). A structuration analysis of organizational climates. In L. Putnam \& M. Pacanowsky (Eds.), Communication and organizations: An interpretive approach (pp. 195-220). Beverly Hills, CA: Sage Publishing.

Powell, G. (1993). Handbook of Gender and Work. Thousand Oaks, CA: Sage Publishing.

Powell, G., \& Butterfield, D. (1989). The "good" manager: Did androgyny fare better in the 1980's? Group and Organization Studies, 14 (3), 216-233.

Pugh, M., \& Wahrman, R. (1983). Neutralizing sexism in mixed-sex groups: Do women have to be better than men? American Journal of Sociology, 88, 746-762. Putnam, L., \& Pacanowsky, M. (1983). A structurational analysis of organizational climate. In L, Putnam \& M. Pacanowsky (Eds.), Communication and Organizations: An Interpretive Approach (pp.173-194). Beverly Hills, CA: Sage Publishing.

Ridgeway, C. (1997). Interaction and the conservation of gender inequality: Considering employment. American Sociological Review, 62, 218-235.

Ridgeway, C., \& Correll, S. (2004). Unpacking the gender system: A theoretical perspective on gender beliefs and social relations. Gender \& Society, 18, (4), 510531.

Risman, B. (1998). Gender vertigo: American families in transition. New Haven, CT: Yale University Press. 
Salazar, A. (1996). An analysis of the development and evolution of roles in the small group. Small Group Research, 27 (4), 475-503. Thousand Oaks, CA: Sage.

Schein, V. (1973). The relationship between sex role stereotypes and requisite management characteristics. Journal of Applied Psychology, 57 (2), 95-100.

Sheriff, M. (1941). Group influence upon the formation of norms and attitudes. In E. Macoby, T. Newcomb, \& E. Hartley, (Eds.), Readings in social psychology (pp. 219-232). New York: Holt, Rinehart \& Winston.

Still, L. (1994). Where to from here? Women in management - the cultural dilemma. Women in Management Review, 9 (4), 3-10.

Syvensky, J.M., \& Madden, J.L. (1996). Effects of gender and sex type on perceived leadership ability. Journal of Group Psychotherapy, 49 (2), 76-88.

Tedeschi, J., \& Rosenfeld, P. (1987). Communication in bargaining and negotiations. In M.E. Roloff \& G. Miller (Eds.), Persuasion: New directions in theory \& research (pp. 225-281). Newbury Park, CA: Sage Publishing.

Valian, V. (1998). Why So Slow? Cambridge, MA: The MIT Press.

Webster's Dictionary. (1963). H. Wild \& E. Partridge (Eds.), New York: J.J. Little \& Ives.

White, B., \& Cox, C. (1991). A comparison of the characteristics of female managers and female entrepreneurs, Women in Management Review, 6 (2), 17-24.

Wilen, T. (2000). A new survey finds that women who work for high-tech firms still believe in the glass ceiling. Retrieved June 8, 2005 from www.graduatingengineer.com/articles/feature/2-15-00.html.

Wirth, L. (1997, April). Breaking through the glass ceiling: Women in management. 
Report for discussion at the Tripartite Meeting on Breaking through the Glass Ceiling: Women in Management International Labour Office. Geneva. 